Western University Scholarship@Western

1978

\title{
A Model of Fertility and Children's Schooling
}

Nigel Tomes

Follow this and additional works at: https://ir.lib.uwo.ca/economicsresrpt

Part of the Economics Commons

Citation of this paper:

Tomes, Nigel. "A Model of Fertility and Children's Schooling." Department of Economics Research Reports, 7826. London, ON:

Department of Economics, University of Western Ontario (1978). 
RESEARCH REPORT 7826

\section{A MODEL OF FERTILITY AND \\ CHILDREN'S SCHOOLING}

by

Nige1 Tomes

August, 1978 
A MODEL OF FERTIIITY AND CHIIDREN'S SCHOOLING

\author{
Nige1 Tomes \\ Department of Economics \\ University of Western Ontario \\ Iondon, Ontario, Canada
}

July 1978 


\begin{abstract}
A model of fertility and child schooling is developed using the Quality-Quantity Interaction framework proposed by Becker et al. The relationship between fertility and child schooling is shown to depend on the financial constraints faced by households and whether marginal parent-child transfers are in the form of schooling.

Empirical results confirm that fertility and schooling are simultaneously determined. Due to this interaction, fertility is observed to be negatively related to income and independent of mother's education. However, holding child schooling constant, fertility is positively related to both income and mother's education. These results imply that child numbers are not an inferior comodity and that the growth of women's productivity is not biased agalnst fertility.
\end{abstract}




\section{Introduction}

The empirical observation that measures of achievement, such as IQ, high school grades and years of schooling, are inversely related to the size of the family of origin, represents an empirical regularity in need of an explanation. ${ }^{1}$ In addition, investigators have found the relationship of completed fertility to income and education complex and often puzzling (Simon (1974), Ben Porath (1973)). The recurrent finding that family size is negatively related to income, which implies that numbers of children are an inferior commodity, is inconsistent with the intuition that inferior goods are exceptional and likely to constitute a minor portion of the family budget.

The Quality-Quantity Interaction model developed by Becker and his associates (Becker and Lewis (1973), Becker and Tomes (1976)) offers a unified explanation of these observations. In this model, expenditures per child (quality) and the number of children (quantity) enter multiplicatively in the income-expenditure constraint. Due to this interaction, quality and quantity are predicted to be negatively related and the observed relationship of these variables to parental income and education may diverge substantially from the underlying "true" parameters, which characterize the tastes and technology of the household.

Although it has been demonstrated that the quality-quantity interaction model is consistent with the observed ' $U$ '-shaped relationship between fertility and income, this represents a relatively weak test of the theory. The purpose of this paper is to subject this model to the more stringent test of directly estimating the structural and reduced form equations. 
Previously, child quality has been equated with total parental expenditures on children. However such expenditures may take on a number of forms such as child care, schooling and medical care--which are dimensions of human capital or gifts and bequests of material wealth--which are components of non-human capital. When parental expenditures take several forms, the interaction of quality and quantity may be reflected in some components and not in others. I show that whether this interaction is reflected in the relationship between fertility and human capital investment depends upon the financial constraints faced by households and whether intergenerational transfers of material wealth are being made.

The quality-quantity interaction framework can be used to generate different models under alternative assumptions concerning tastes, household technology and financial constraints. In this paper I specitya model that captures the salient features of this class of model and produces testable implications which are capable of being refuted by the data. Based upon this mode1, predictions are derived concerning the simultaneous determination of fertility and children's schooling. Both the structural demand functions, which reflect the "true" behavioral parameters, and the reduced form (observed) demand functions are derived and predictions are obtained concerning the effects of parental income and education. Information on a sample of high ability individuals is used to estimate the structural and reduced form equations of the model. The empirical results confirm the importance of quality-quantity interaction. The level of children's schooling enters as a significant determinant of fertility and vice versa. As a consequence of this interaction, the observed relationships of fertility and children's schooling to parental characteristics differ substantially from the true relationships. In particular, fertility is observed to be negatively related to measures of parental income and unrelated to mother's 
education. However, once schooling is held constant, family size is found to be positively related to both income and female education, implying that numbers of children are not an inferior commodity and that fertility is increased as a direct result of the growth of women's productivity. Significant differences are found between male and female subsamples, which suggest that females may have faced greater constraints in financing their education, than did their male counterparts.

The plan of the remainder of this paper is as follows. Section 2 presents the theoretical model and derives predictions concerning the structural and reduced form demand functions for quality and quantity. The empirical counterpart of the theoretical model is specified in Section 3. Empirical results are reported in Section 4 and Section 5 presents the conclusions.

2. A Model of Quality-Quantity Interaction

Assume a static and certain world in which individuals possess perfect foresight. Generations of the family are assumed to be both interdependent and overlapping. Parental fertility and parent-child transfers of resources are assumed to be motivated by pure altruism, ${ }^{2}$ such that the number of offspring and their per capita income enter as arguments, together with parental consumption, in the utility function of the parental decisionmakers:

$$
\mathrm{U}=\mathrm{U}\left(\mathrm{n}, \mathrm{I}_{\mathrm{C}}, \mathrm{y}\right)
$$

where $U$ is the utility function of parents, $n$ their number of children produced. $I_{C}$ is the per capita income of children during their subsequent tenure as parents, and is assumed to be the same for all $\mathrm{n}$ children. ${ }^{3} \mathrm{y}$ represents the aggregate of all other commodities--"parental consumption"。

The income of the next generation depends upon the endowment of children and parental transfers. It is assumed that the endowed income of children, which results from government fiscal policy, exogenous economic growth and 
other factors, is the same for all individuals within the same generation.$^{4}$ The per capita income of children may be augmented by transfers of both human and non-human capital, subject to the technology described by the income generating function:

$$
I_{C}=e+a(X, \beta) X+g=e+q+g
$$

where

$$
q=a(x, \beta) x \text { and } a_{x} \leq 0, a_{\beta} \geq 0
$$

The right-hand side of (2) defines three proximate determinants of the per capita income of children: $e, q$ and $g$, which represent the income due to endowments, human capital transfers and non-human capital ("asset") transfers, respectively. This particular parameterization assumes that the return on asset transfers is constant and independent of the scale of human capital transfers. Considerations, such as the finiteness of individual capacities and the limited length of life, suggest that transfers of human capital may be subject to diminishing returns with respect to additional parental expenditures (i.e., $a_{x} \leq 0$ ), where $x$ represents the aggregate parental input. Parental efficiency $(\beta)$ is assumed to operate in a manner equivalent to technological progress, increasing the income of the next generation, for given inputs (i.e., $\left.a_{\beta} \geq 0\right) 0^{5}$ Parental human capital is assumed not only to produce parental income, but also to increase the ability of parents to generate income for their offspring.

In the absence of any "family" (public) goods components, ${ }^{6}$ expenditures on the next generation are simply the product of per capita transfers and the number of children, valued at the appropriate prices, i.e.:

$$
I_{P}=P_{y} y+P n X+P_{g} n g
$$

where $I_{P}$ represents the income of parents, $P_{y}$ the price of the consumption 
commodity, $P$ the price per unit of human capital inputs, and $P_{g}$ the price of increasing the per capita asset income of the next generation by $\$ 1$. PnX, therefore represents the total expenditures on the human capital of the next generation and $P_{g} n_{g}$ the total expenditures on asset transfers. The vector of "market prices" $\left(P_{y}, P, P_{g}\right)$ will depend in general on the prices of parental time and goods inputs, tax rates and rates of return. However these prices are assumed independent of the level of expenditures.

Maximizing the parental utility function (1) subject to (2) and (3) yields the first order conditions :

$$
\begin{aligned}
& \frac{U_{y}}{\lambda}=P_{y} \equiv \Pi_{y} \\
& \frac{U_{C}}{\lambda}=\frac{P_{n}}{a(\cdot)(1-\eta)}=P_{g} n \equiv \Pi_{I} \\
& \frac{U_{n}}{\lambda}=P X+P_{g} g=\frac{P q}{a(\cdot)}+P_{g} g \equiv \Pi_{h}
\end{aligned}
$$

where

$$
a(\cdot)=a(x, \beta), \eta \equiv-a_{x} x / a(\cdot), 0 \leq \eta<1 . \lambda \text { is the marginal }
$$

utility of parental income and $U_{j}$ is the marginal utility of commodity $j$.

The marginal rate of substitution between each commodity and parental income is equated to the marginal cost of that commodity defined by the first order conditions $\left(\Pi_{j}\right.$ for commodity $j$ )。 The marginal costs of quality and quantity $\left(\Pi_{I}\right.$ and $\Pi_{n}$, respectively) differ from the usual ones in that they depend not only on market prices, but also on the level of commodity outputs. The marginal cost of quality is positively related to the number of children, and conversely, the marginal cost of numbers is positively related to the level of income transfers. This property, characteristic of quality-quantity interaction models, has important implications. First, it implies that in order to directly estimate the underlying income and substitution parameters, measures 
of quality should enter the demand function for numbers, and measures of quantity should enter the demand function for quality.

Although quality and quantity are predicted to be inversely related, whether this interaction is reflected in human or non-human transfers depends critically on the financial constraints facing households. For example, if there is an infinttely elastic supply of parental loans to children during their overlapping tenure to finance human capital investment, or if parents can bequeath financial debt at the end of their life, the level of human capital transfers would be independent of the "opportunities" defined by parental income and family size. 8 In this case the traditional Fisherian separation would exist between investment and consumption decisions. The optimum level of human capital transfers would be determined by parental efficiency and the child's endowment, while the level of child's income would be determined by utility maximization considerations. The level of asset wealth or debt transfers represents the residual degree of freedom which renders these two decisions consistent. Qualityquantity interaction would then be reflected in the relationship between asset transfers and numbers, and the level of human capital transfers would be independent of the level of fertility.

Observation suggests that there may not exist complete equality of opportunity across families. In order to capture this element, while allowing for differences in the financial constraints faced by different families, I make a number of assumptions. First, assume all human capital investment is financed internally to the family and there are no intergenerational loans. Second, I impose the financial liablifty constraint:

(7) $\quad \mathrm{g} \geq 0$

that is, parents cannot Impose financial debt on their children. Since the 
predictions of the model differ according to whether the financial liability constraint is effective or not, I shall first examine the case where this constraint is binding so that asset transfers are zero and then indicate how these predictions are affected if this constraint is not binding. Human Capital Transfers and Fertility, when Asset Transfer are Zero

When asset transfers are zero, the first order conditions (5) and (6) simplify to

(5), $\frac{\mathrm{U}_{\mathrm{I}_{\mathrm{C}}}}{\lambda}=\frac{\mathrm{Pn}}{\mathrm{a}(\beta)} \equiv \Pi_{I}$

(6) $\frac{U_{n}}{\lambda}=P X=\frac{P q}{a(\beta)} \equiv \Pi_{n}$

where it has also been assumed, for simplicity, that the returns to human capital investment are constant (i.e., $a_{x}=0$ ). Under these assumptions the marginal costs of quality and numbers are related in a simple manner--the ratio of the marginal cost of quality to that of quantity equals the ratio of numbers to quality (i.e., $\Pi_{I} / \Pi_{n}=n / q$ ).

Since the appropriate marginal costs defined by the first order conditions depend on the level of commodity outputs, changes in parental income and market prices $\left(\mathrm{P}_{i}\right.$ 's) will not produce "pure" income and substitution effects. However, a set of demand functions can be defined in terms of the marginal costs $\left(\Pi_{i}^{2} s\right)$ and a related income measure, which permit the traditional separation of pure income and substitution effects. The appropriate income construct is the value of the commodities which enter the objective function (1), valued at marginal cost (Becker and Lewis (1973)). Denoting this by $\mathrm{R}$ :

$$
R=\Pi_{y} y+\Pi_{n} n+\Pi_{I} I_{C}=P_{y} y+P n X+P * n I_{C}=I_{P}+P * n I_{C}
$$

where $P *=P / a(\beta)$. 
The level of resources $R$ equals parental income, plus the income of the next generation, valued at the price of human capital transfers ( $\mathrm{P} *$ ). The set of "true" demand functions relate the levels of commodities demanded to the level of real resources and relative marginal costs, and reflect the income and substitution parameters that characterize the utility function. The true demand functions for numbers and quality may be written as:

$$
j=f_{j}\left(\frac{R}{\Pi}, \frac{\Pi}{\Pi}, \frac{\Pi_{n}}{\Pi}, \frac{\Pi_{I}}{\Pi}\right) \quad j=n, q
$$

where $\Pi$ is an index of marginal costs $\left(\Pi_{1}^{\prime} ' s\right)$ and $\bar{P}$ is an index of market prices ( ${ }_{i}$ 's). The demand for child quality is an excess demand function for child's income, given their endowment. In (9) the level of real resources depends upon parental income and efficiency, while relative marginal costs depend on market prices, child numbers, quality and parental efficiency.

In the "true" demand functions the endogenous variables--numbers and equality--enter as determinants of the marginal costs. I assume that these equations can be solved explicitly for numbers and quality to obtain the following "structural" demand functions:

(10) $\left\{\begin{array}{l}n=b_{n}\left(\frac{R}{\Pi}, \frac{\Pi_{y}}{\Pi}, \frac{\Pi_{n}}{\Pi}\right)=c_{n}\left(\frac{I_{p}}{\bar{P}}, \frac{P}{P}, \frac{P}{\bar{P}}, q, \beta\right) \\ q=b_{q}\left(\frac{R}{\Pi}, \frac{\Pi_{y}}{\Pi}, \frac{\Pi_{I}}{\Pi}\right)=c_{q}\left(\frac{I_{P}}{P}, \frac{P}{P}, \frac{P}{\bar{P}}, n, \beta\right)\end{array}\right.$ 
In the structural demand for numbers, transfers enter as a determinant of the marginal cost of numbers. However, since child numbers do not enter as an argument, the marginal cost of quality will vary in response to changes in the exogenous variables. Similarly child numbers enter the demand function for human capital transfers, while the marginal cost of numbers is permitted to vary. However, although the magnitudes of response implied by the structural demand functions will differ in general from their true counterparts, the signs and relative magnitudes of response in these two equations are unaffected. In the special case in which the utility function is CES with equal elasticities of substitution between all commodities, ${ }^{9}$ it is shown in the appendix that these demand functions can be written in 1 og derivative form as : ${ }^{10}$ $(10):\left\{\begin{array}{l}d \ln n=\frac{1}{\left(1-K_{I} \sigma\right)}\left\{\left(1-K_{I}\right) d \ln I_{\bar{P}}+\left(K+K_{y} \sigma\right) d \ln \beta-(1-K) \sigma d \ln q\right\} \\ d \ln \cdot q=\frac{1}{A\left(1-K_{I} \sigma\right)}\left\{\left(1-K_{I}\right) d \ln I_{\bar{P}}+\left(K+K_{y} \sigma\right) d \ln \beta-\left(1-K_{I}\right) \sigma d \ln n\right\}\end{array}\right.$ where $K_{j}=\Pi_{j} j / R, K=$ Pnq $/ R, A=q / I_{C},\left(1-K_{I} \sigma\right)>0, I_{\bar{P}}=I_{P} / \bar{P}$, and $\sigma$ is the common elasticity of substitution. In $(10)^{8}$ it has been assumed that all market prices are constant and a $1 \%$ increase in household efficiency is assumed to raise the marginal product of parental inputs by $1 \%$ In the structural demand function quality enters as a determinant of the marginal cost of numbers and vice versa in the quality equation. Since both commodities have a negative own-price elasticity both variables enter with a negative sign. An increase in parental efficiency, since it lowers the marginal cost of both quality and quantity relative to the third commodity and increases the level of real resources, is associated with an increase in demand for both commodities. Both numbers and quality are predicted to exhibit positive structural income elasticities. 
Consider now the set of "observed" demand functions, which result from solving the system (10) simultaneously for the comodity outputs. The observed demand functions contain as arguments parental income and efficiency, and market prices :

$$
\left.j=h_{j} \frac{P}{P}, \frac{P}{P}, \frac{P}{P}, \beta\right) \quad j=n, I_{C}, y \cdot
$$

The "observed" demand functions depend on the same underlying parameters as the true and structural demand functions. However, since holding market prices constant does not hold marginal costs constant, the observed elasticities will differ in general from their true counterparts. The important point is that although the structural parameters differ only in magnitude from their true counterparts, the observed relationships may differ both in sign and magnitude from the underlying true parameters. This point can be illustrated by considering again the case in which all income and substitution elasticities are equal. In this special case the observed demand functions for quantity and quality are:

$$
\left\{\begin{array}{l}
D d \ln n=\left[1-\frac{\sigma}{A}\right]\left\{\left(1-K_{I}\right) d \ln \frac{I_{\bar{P}}}{\mathrm{P}}+\left(\mathrm{K}+\mathrm{K}_{\mathrm{y}} \sigma\right) d \ln \beta\right\} \\
D d \ln q=\left[\frac{1-\sigma}{\mathrm{A}}\right]\left\{\left(1-\mathrm{K}_{I}\right) d \ln \frac{I_{\bar{P}}}{\mathrm{P}}+\left(\mathrm{K}+\mathrm{K}_{\mathrm{y}} \sigma\right) d \ln \beta\right\}
\end{array}\right.
$$

where $\mathrm{D}>0$ is defined in the appendix, and $0 \leq \sigma<1,0<\mathrm{A} \leq 1$.

In both equations the coefficients on parental income and efficiency differ from those in the corresponding structural equation (10)' by a factor of proportionality, which reflects the interaction of quality and quantity. In the demand function for human capital transfers the factor of proportionality is positive, and the observed elasticities exceed (fall short of) the corresponding 
structural elasticities if the elasticity of substitution is greater (1ess) than the share of transfers in children's total income. In contrast, the factor of proportionality by which the observed and structural demand functions for numbers differ may take on either sign, being negative (positive) if the elasticity of substitution exceeds (falls short of) the share of transfers in the next generation's income. The intuitive reason for this result can be illustrated by considering the effects of an increase in parental efficiency. An increase in parental efficiency by raising the marginal product of inputs into the next generation's human capital, lowers the price of both quality and quantity relative to that of parental consumption and in addition increases real income. Both income and substitution effects increase the demand for numbers and child's income--in this qecial case by the same percentage. This implies that parent-child transfers increase relative to child numbers (see fn。 10), thereby increasing the marginal cost of numbers relative to quality and inducing further substitution effects. If these secondary substitution effects are sufficiently great (i॰e., $\sigma>A$ ) the observed relationship between numbers and parental efficiency will be negative, even though the direct (structura1) relationship is positive. 11 Human Capital Transfers and Fertility, when Asset Transfers are Positive When asset transfers are positive, the financial liability constraint (7) is not effective and the predictions concerning the demand functions for human capital transfers and numbers differ from those discussed above。 12 First, the demand for human capital transfers is independent of parental income and family size and depends only on the rate of return on human capital investments relative to that on assets. An increase in parental efficiency, since it raises the rate of return on human capital relative to assets 
continues to be associated with an increase in human capital transfers. Second, since the marginal cost of numbers depends on the level of both human capital and asset transfers (see equation (6)) both these variables should enter the structural demand function for numbers. When the level of asset transfers is not held constant, and represents either an omitted or unobserved variable, the marginal cost of numbers is not held constant while considering the effects of parental income and efficiency on fertility. In this situation the demand function for numbers which holds human capital transfers constant corresponds more closely to the observed demand function $\left((11)\right.$ and $\left.(11)^{2}\right)$ than the structural equation $((10)$ and (10)'). It can be shown (Tomes (1978), pp. 177-180) that, when the utility function is CES, the elasticity of numbers with respect to parental income, holding human capital transfers constant, is positive (negative) as the share of transfers in the child's income is greater (1ess) than the elasticity of substitution--the same condition as that which determines the effect of income in the observed demand function. ${ }^{13}$ The intuitive reas on is clear-an increase in income, since it leaves the rates of return on different types of transfer unaffected, will be reflected entirely in increased asset transfers. Therefore holding human capital transfers constant does not hold marginal transfers and therefore the marginal cost of numbers constant. Induced substitution effects due to quality-quantity interaction occur, which cause the relationships to diverge from the underlying true parameters.

Having noted how the nature of the financial constraints and the introduction of other types of marginal transfer may influence the predictions of the $=$ theoretical model, I shall proceed to specify an empirical version of the model on the assumptions that the utility function is CES, with equal elasticities of substitution, human capital constitutes the only form of intergenerational transfer and that the financial liability constraint is 
binding upon all households. Any divergence between the results and the theoretical predictions of this model will be examined in the light of the predictions of the more general model.

\section{Empirical Specification}

The data set that I shall use to estimate equations $(10)^{8}$ and $(11)^{8}$ is the "Terman" sample of high IQ individuals. These data derive from a study initiated in 1921 by Iewis M. Terman, a Stanford psychologist. The sample consists of a total of 1,468 individuals (822 males and 646 females) selected as children from the California school system on the basis of an IQ test score in excess of 135 and who therefore fall in the upper tail of the IQ distribution. The empirical measures corresponding to the theoretical variables are briefly described here and summarized in Table 1 . The number of siblings were reported in 1940, at which time the parents were sufficiently old to constitute a completed fertility cohort. The level of schooling achieved by 1950 (when the average age of children was 39) was used as a measure of parental transfers of human capital. In terms of the theoretical model this variable has shortcomings since it neglects preschool investments and also the quality of schooling. However, it has the advantage of being a "global" measure of human capital and of being closely related to the income of children.

In the absence of direct information on parental income, two measures were used to proxy lifetime income. The first is an index of relative income based upon the father's occupation in 1922 and 1927. The second index of income is based upon retrospective information provided by the offspring concerning the adequacy of family finances during their childhood and youth. As measures of parental efficiency I use the levels of education and the ages 


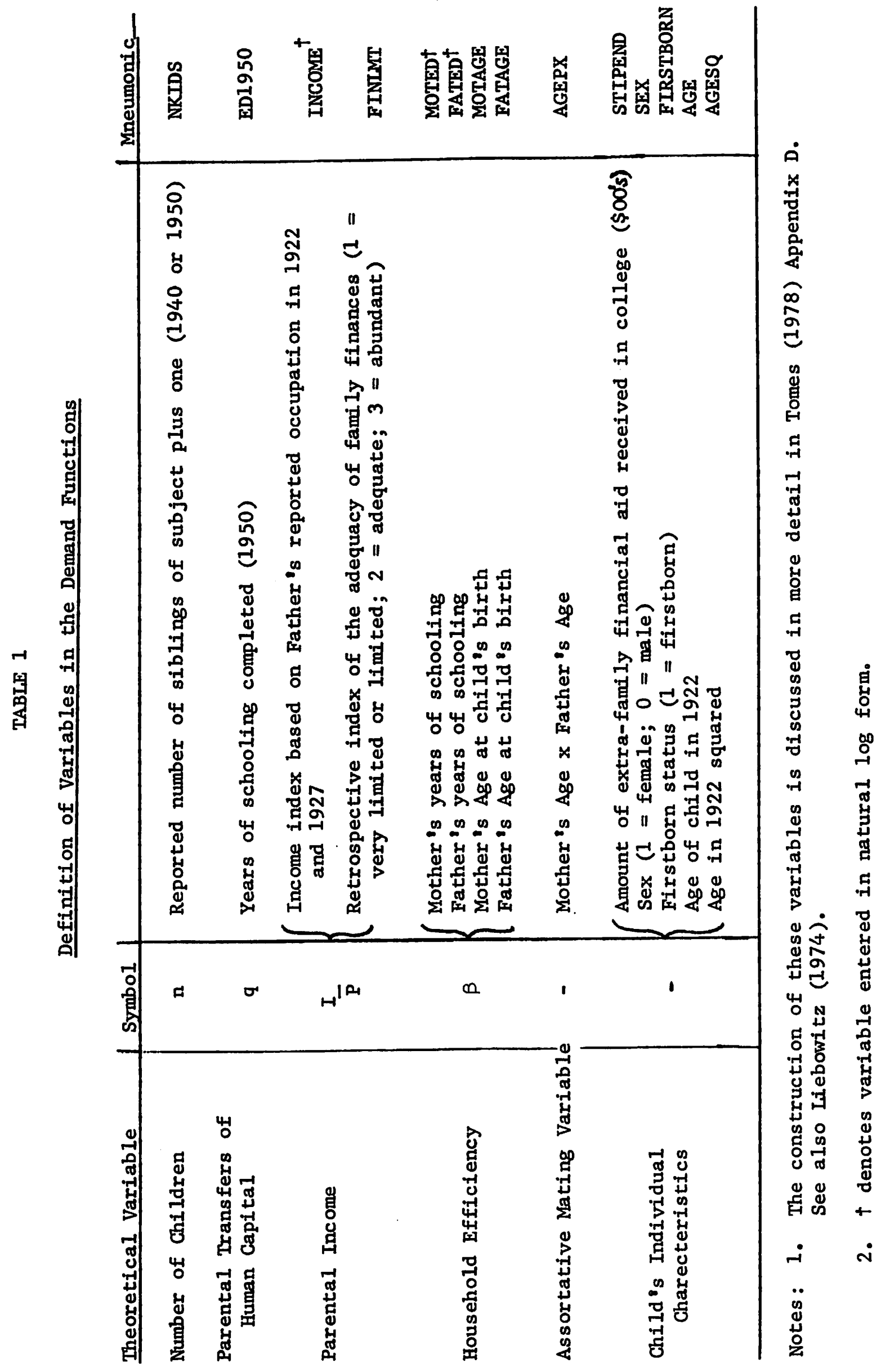


of parents. Since the data contain no information on the wage rates of parents, these variables measure the effects of increased efficiency in household production and also via increased market wage rates. 14

In addition to measures of parental income and efficiency a number of additional variables were introduced. First, the theories of marriage and specific investment under uncertainty (Becker et a1。(1977)) suggest the inclusion of variables reflecting the degree of assortative mating between parents in terms of various traits. For this reason an interaction term between the ages of parents was introduced and is predicted to be positively related to marriage specific investments in children. ${ }^{15}$ second, since the theoretical variable relates to the average level of human capital transfers to children, whereas the empirical observations relate to one child, variables relating to the child's individual characteristics--age, sex and the extent of extra-family financial aid while in college--were included in both structural equations and the reduced form equation for schooling. 16 Third, the possibility that families differ in the financial constraints that they face suggests the inclusion of additional interaction terms, including an interaction term between mother's education and the extent of extra-family financial aid. This interaction term is predicted to have a negative coefficient in the schooling equation. 17

In order to estimate the structural equations or to retrieve the structural coefficients from the reduced form equations it is necessary to impose somewhat arbitrary, though defensible identifying restrictions. Two alternative assumptions were made concerning the structural equation for numbers-- first, that this equation is linear in the $\log$ of mother's education and second, that holding the level of schooling constant, family size is independent of father's 
education. $^{18}$ similarly, two alternative assumptions were made concerning the child's schooling equation--that it is unaffected by father's age or the interaction between parents' ages, holding child numbers constant. The latter assumption implies that differences in the expected duration of marriage due to age differences between spouses will be reflected in the choice of family size and not in the level of parent-child transfers. ${ }^{19}$

The empirical structural demand functions for child numbers and schooling can be written in terms of the mneumonics defined in Table 1 as :

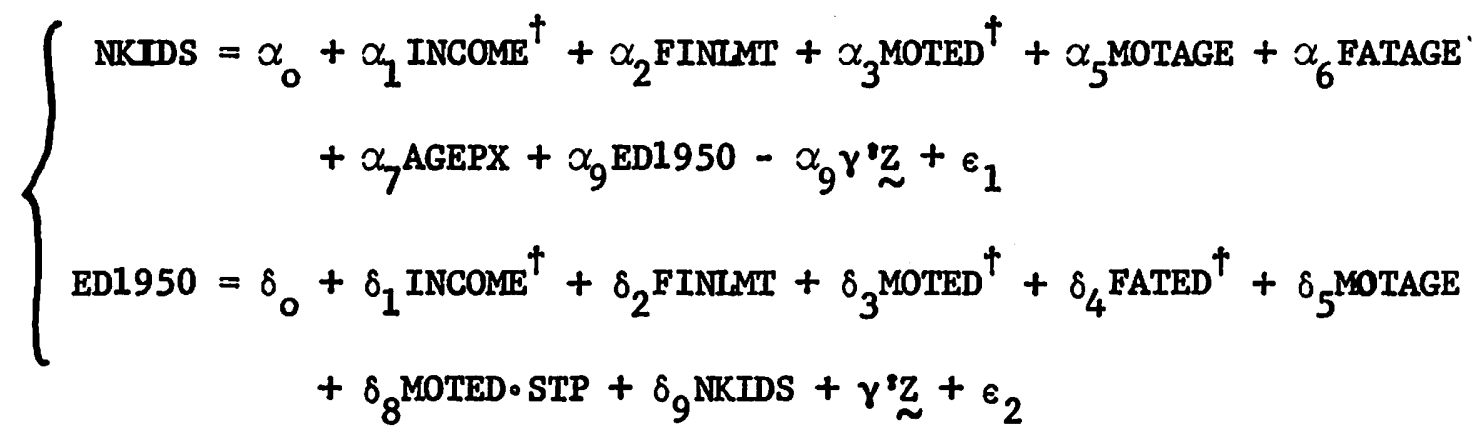

where $t$ denotes the natural $10 g$ of the variable, $z$ represents the vector of individual characteristics (see fn, 16) and $\epsilon_{1}$ and $\epsilon_{2}$ represent random error terms assumed to be distributed independently of the exogenous variables and of each other. As specified these equations embody the identifying restrictions $\alpha_{4}=\alpha_{8}=0$ and $\delta_{6}=\delta_{7}=0$.

The corresponding reduced form (observed) demand functions are:

$$
\begin{aligned}
& \left\{\begin{aligned}
\text { NKIDS }= & \left(1-\alpha_{9} \delta_{9}\right)^{-1}\left\{\left(\alpha_{0}+\alpha_{9} \delta_{0}\right)+\left(\alpha_{1}+\alpha_{9} \delta_{1}\right) \text { INCOME }^{\dagger}+\left(\alpha_{2}+\alpha_{9} \delta_{2}\right)\right. \text { FINIMT } \\
& +\left(\alpha_{3}+\alpha_{9} \delta_{3}\right) \text { MOTED }^{\dagger}+\alpha_{9} \delta_{4} \text { FATED }^{\dagger}+\left(\alpha_{5}+\alpha_{9} \delta_{5}\right) \text { MOTAGE }+\alpha_{6} \text { FATAGE } \\
& \left.+\alpha_{7} \text { AGEPX }+\alpha_{9} \delta_{8} \text { MOTED STP }+\left(\epsilon_{1}+\alpha_{9} \epsilon_{2}\right)\right\} \\
\text { ED1950 }= & \left(1-\alpha_{9} \delta_{9}\right)^{-1}\left\{\left(\delta_{0}+\delta_{9} \alpha_{0}\right)+\left(\delta_{1}+\delta_{9} \alpha_{1}\right) \text { INCOME }^{\dagger}+\left(\delta_{2}+\delta_{9} \alpha_{2}\right)\right. \text { FINLMT }
\end{aligned}\right. \\
& +\left(\delta_{3}+\delta_{9} \alpha_{3}\right) \text { MOTED }^{\dagger}+\delta_{4} \text { FATED }^{\dagger}+\left(\delta_{5}+\delta_{9} \alpha_{5}\right) \text { MOTAGE }+\delta_{9} \alpha_{6} \text { FATAGE } \\
& \left.+\delta_{9} \alpha_{7} \text { AGEPX }+\delta_{8} \text { MOTED.STP }+\left(\epsilon_{2}+\delta_{9} \epsilon_{1}\right)\right\} \\
& +\gamma^{2} Z
\end{aligned}
$$


The coefficients in equation (12) correspond to the structural parameters of equation (10)'. Both income variables and mother's education are predicted to enter both equations with positive coefficients. This latter prediction, concerning the effect of mother's education on fertility differs from that of other models of fertility which emphasize the time intensity of numbers of children, and therefore predict that increased mother's education will be associated with smaller numbers of children (De Tray (1973), Ben Porath (1973)). The level of child's schooling is predicted to enter with a negative coefficient in the NKIDS equation and the number of children enters with a negative coefficient in the ED1950 equation--reflecting the interaction of quality and quantity.

The coefficients of equation (13) correspond to the parameters of the observed demand functions (11)?. In the schooling equation parental income and education variables are predicted to enter with positive coefficients. In contrast the INCOME and MOTED variables may take on either sign in the NKIDS equation. If the elasticity of substitution exceeds the share of transfers in child's income, all three variables will enter the reduced form (observed) demand function with negative coefficients, while the corresponding structural coefficients are positive. These predictions represent the most important implications of the simple model of quality-quantity interaction that will be subjected to empirical test in the next section.

4. Empirical Results

In this section I present empirical estimates of the reduced form equations (13) using Ordinary Least Squares (OLS) techniques and estimates of the structural equations (12) using Instrumental Variable (IV) techniques. Also, since numbers of children represent a discrete variable, the equations for NKIDS were also estimated using logistic techniques which take account of this property. First, I report results for the whole sample and then briefly present results separately for the female and male subsamples. 
Table 2 presents the results for the whole sample, estimates of the reduced form equations appear in the upper portion and those of the structural equations in the lower portion. In terms of the INCOME variable the observed income elasticity of schooling is 0.15 . The retrospective income variable (FINIMT) implies that children from families with "adequate" finances received an additional $21 / 2$ months and those with "abundant" family finances an additional 5 months of schooling compared to those with only "limited" famly finances. The observed income elasticity of demand for numbers is negative and approximately equal to -0.5. The FINLMT variable also enters wlth a negative coefficlent indicating a negative observed income elasticity for numbers. In terms of the underlying parameters of equation (11)", this result implies that the elasticity of substitution exceeds the share of parental transfers in the next generation's income. The parental education variables enter with positive coefficients in the schooling equation, but are not significantly different from zero in the numbers equation. This latter result is contrary to the predictions of the theoretical model. The MOTAGE variable enters the schooling equation with a positive coefficient and the numbers equation with a negative coefficient--results consistent with the interpretation of this variable as reflecting the efficiency of the mother acquired during the course of the 11fecycle. The age interaction term (AGEPX) is associated with greater numbers of children and less education per child, suggesting that the major impact of martal sorting by age is upon the number of children. The interaction term between mother's education and the amount of extra-family financial aid is negative in the schooling equation, offering a little evidence that financial constraints may differ across families. This variable is not significant in the numbers equation. 


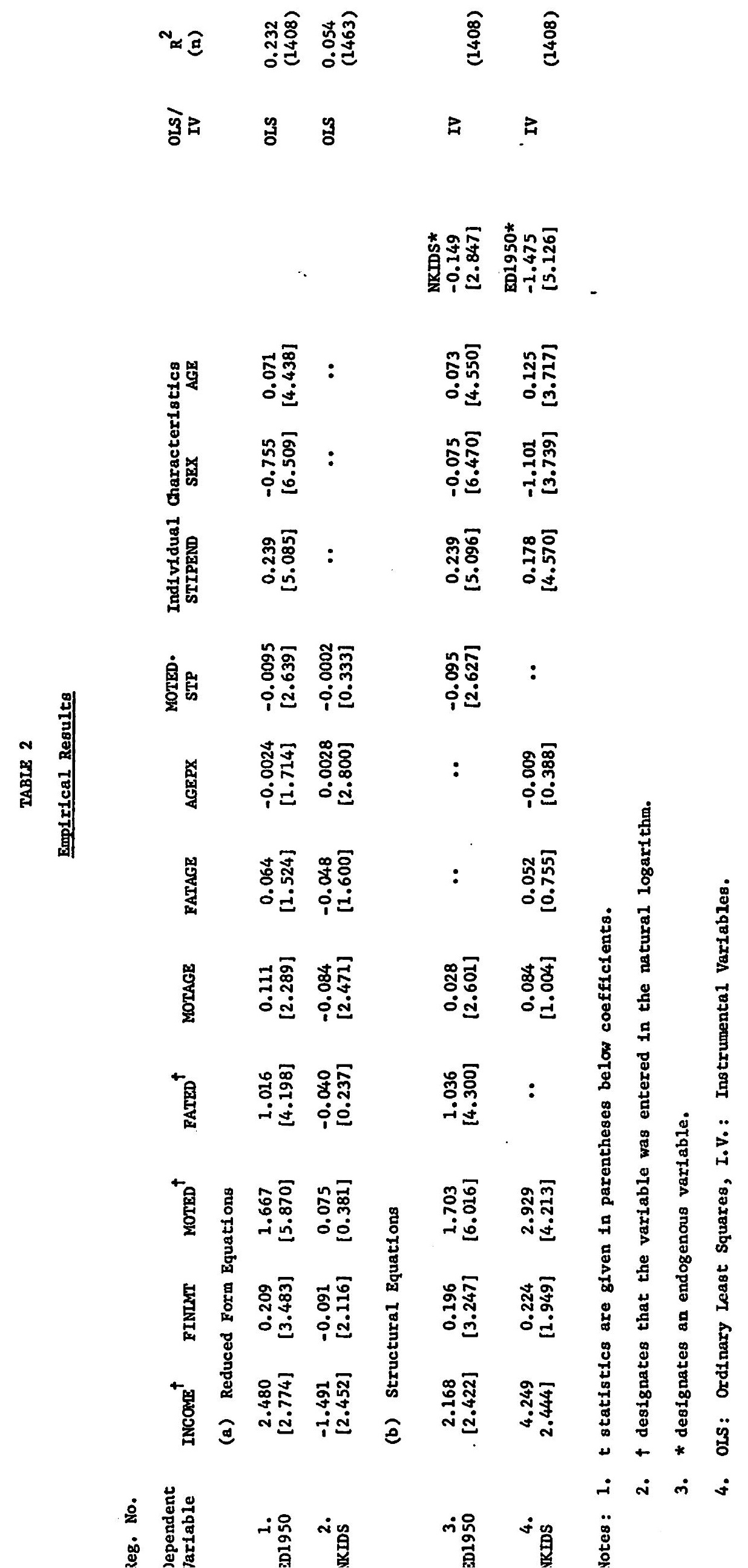


Instrumental variable estimates ${ }^{20}$ of the structural demand functions (12) are presented in the lower portion of Table 2. These results confirm the importance of quality-quantity interaction. The number of children enters as a determinant of child schooling and the level of schooling enters as a determinant of fertility, both coefficients are negative and highly significant. In the schooling equation the structural coefficients differ only slightly from those of the reduced form.

Consistent with the theoretical model the structural demand function for numbers differs more dramatically from its reduced form counterpart. The coefficients on the income variables are positive and significant, implying that the negative observed income elasticity is consistent with an underlying positive true income elasticity and does not imply that children are an inferior commodity. Mother's education, which was not significantly different. from zero in the reduced form equation, enters with a positive structural coefficient. Also, mother's age which entered negatively in the reduced form equation for numbers, is positive, although not significant in the structural equation. These latter two results offer some evidence that increased efficiency on the part of the mother results in greater efficiency in the parentchild transmission of resources and is therefore associated with greater numbers of children. 21 This finding, which has recently been duplicated by Makhija (1978) in the context of rural India, casts doubt on the "traditional" model of the new microeconomic theory of fertility, which emphasizes differences in the time intensity of children versus other commodities and assumes the growth of women's productivity is biased against fertility. (De Tray (1973), Ben Porath (1973)). In the present model, the observed negative relationship between fertility and parental education is consistent with increased parental efficiency increasing the number of children demanded, that is the direct effect of women's productivity is to increase fertility. However since greater parental efficiency also increases the level of child's schooling desired, this raises 
cost of numbers thereby inducing a negative substitution effect which offsets the direct positive effect and results in a negative relationship which masks the underlying true relation. Taken as a whole, these results concerning the parental income, education and age variables offer strong empirical support for the quality-quantity interaction model.

The results reported thus far do not take account of the fact that children may be produced and consumed only in discrete units. Due to this property, the results for the numbers of children may be biased (Press and Nerlove (1973)). The numbers equations were therefore re-estimated using logistic techniques. Table 3 reports the logistic results for the NKIDS structural equation, where the dependent variable is the conditional probability of an additional child for various parities. In all equations the mother's education and income variables enter with positive coefficients and the level of child schooling enters with a negative coefficient in the majority of cases the coefficients are statistically significant. The last line of Table 3 presents the derivative of the expected number of children with respect to the variables, implied by the logistic estimates. The coefficients on some of the variables (notably parental ages). are larger in absolute value than the previous results (see Table 2, equation 4). However the coefficients on the variables that have been emphasized in this study differ only marginally. Given the degree of flexibility of the logistic technique, this is impressive evidence of the robustness of the model to alternative estimation procedures. 


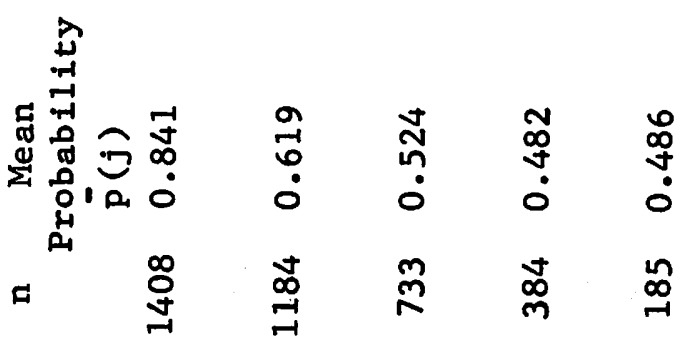

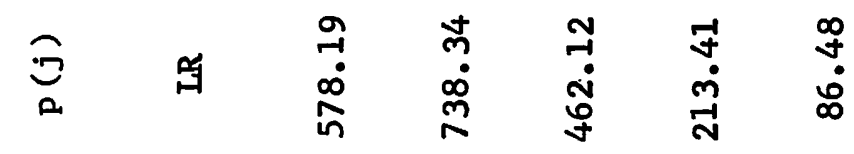

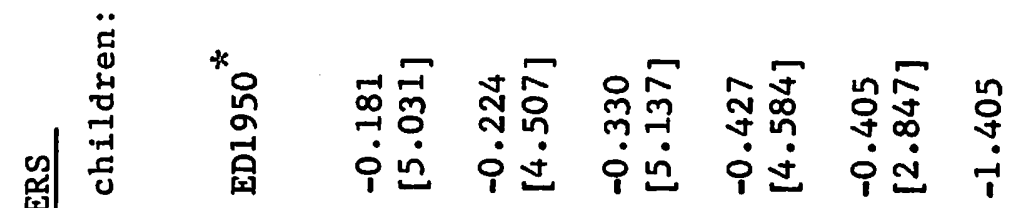

兽|r. a $2 \pi$

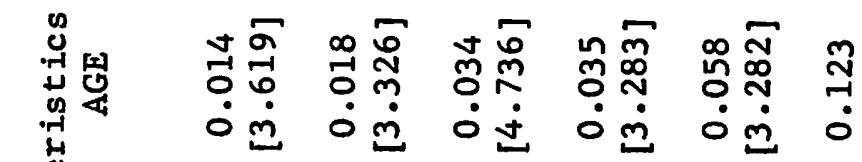

㟧

岕

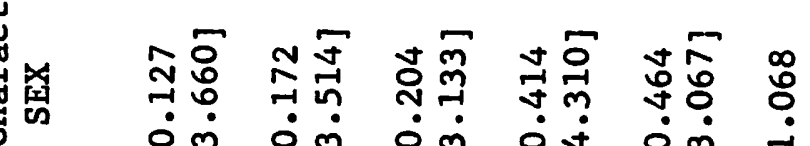
జ

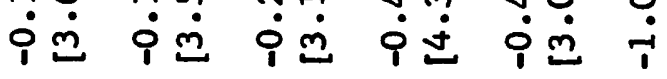

疍

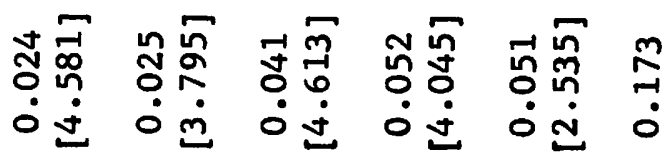

营昆

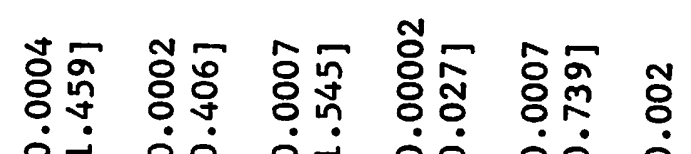

i் $\dot{i} \dot{0} \dot{0} \dot{0} \dot{0} \dot{0}$ i

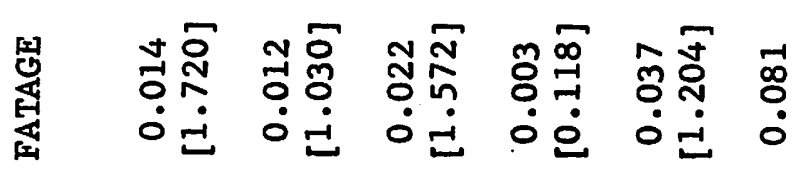

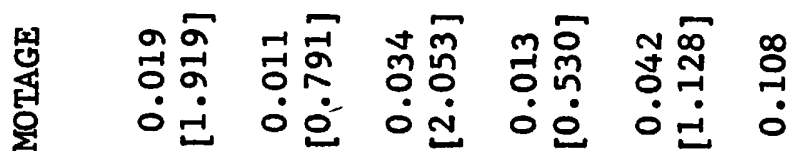

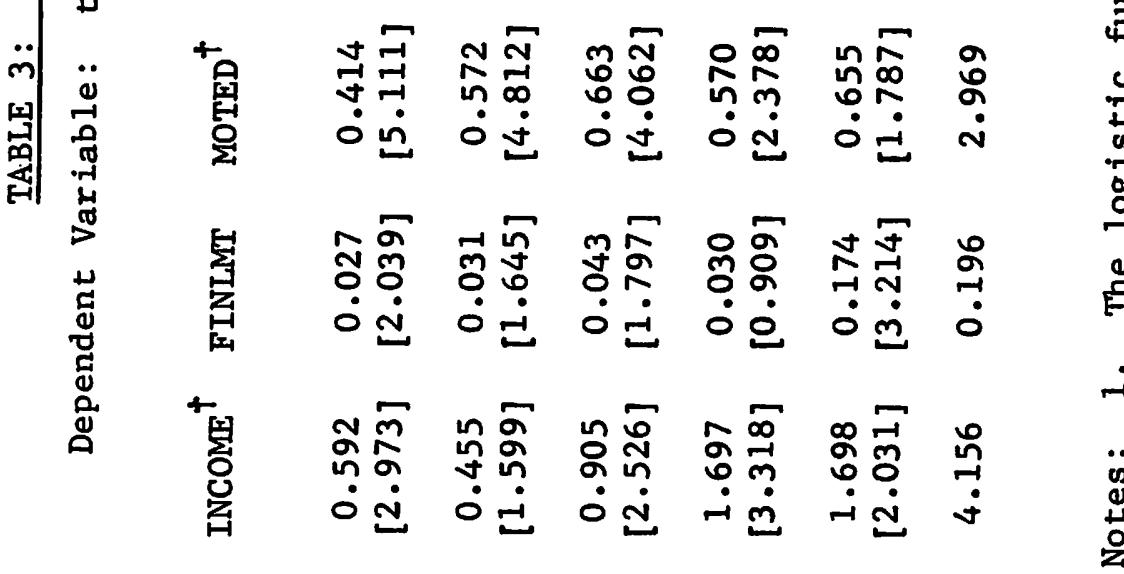

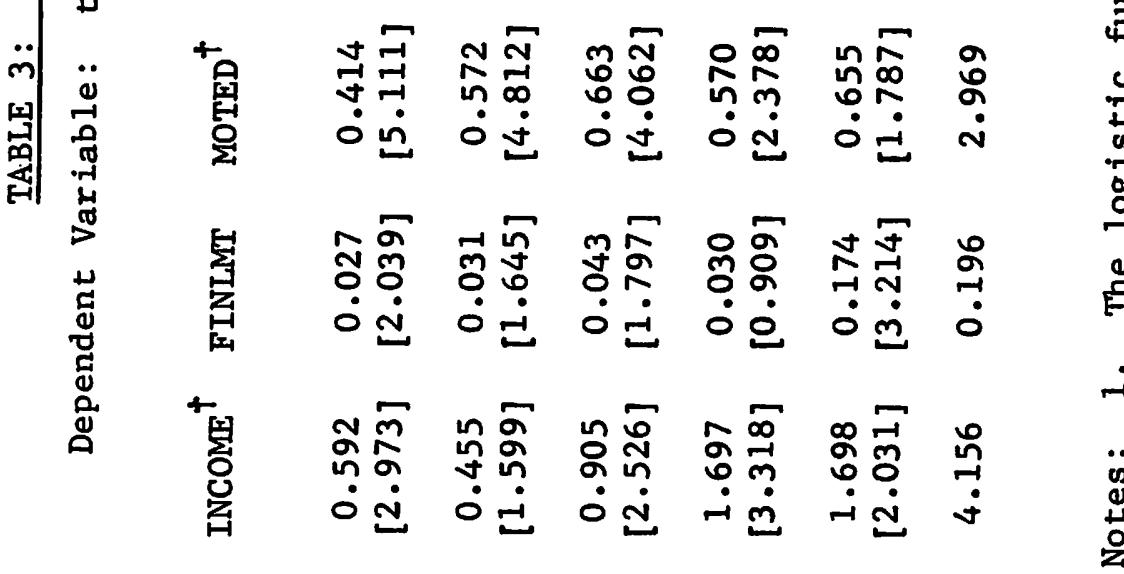

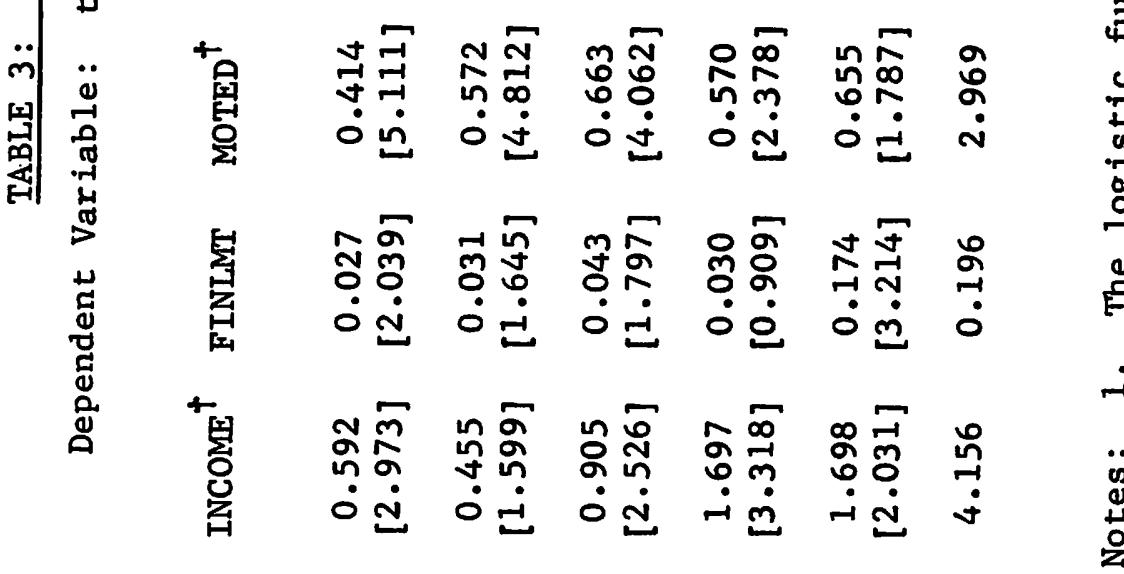

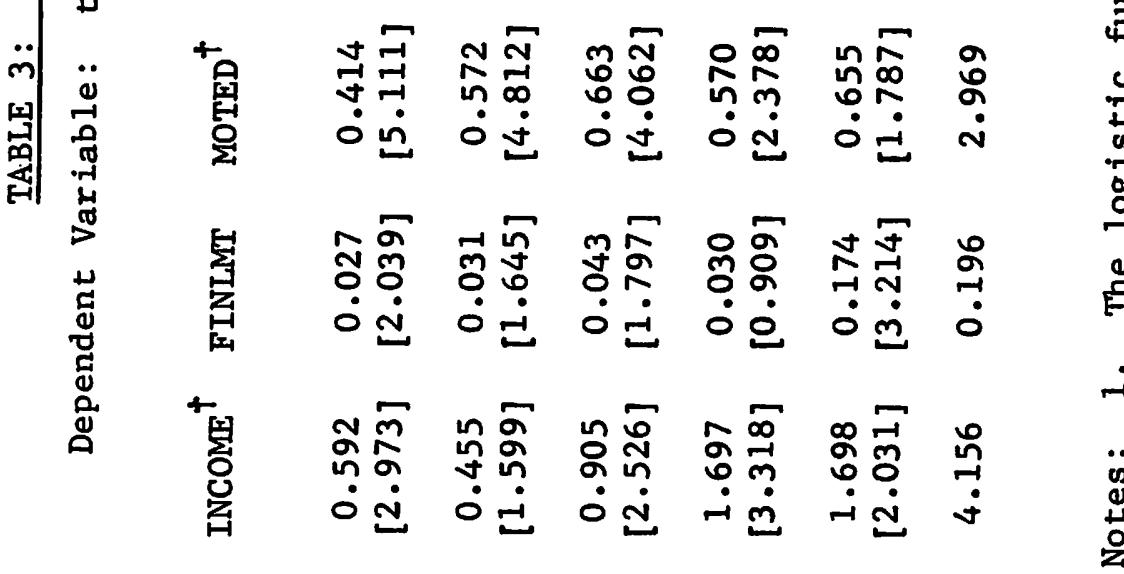

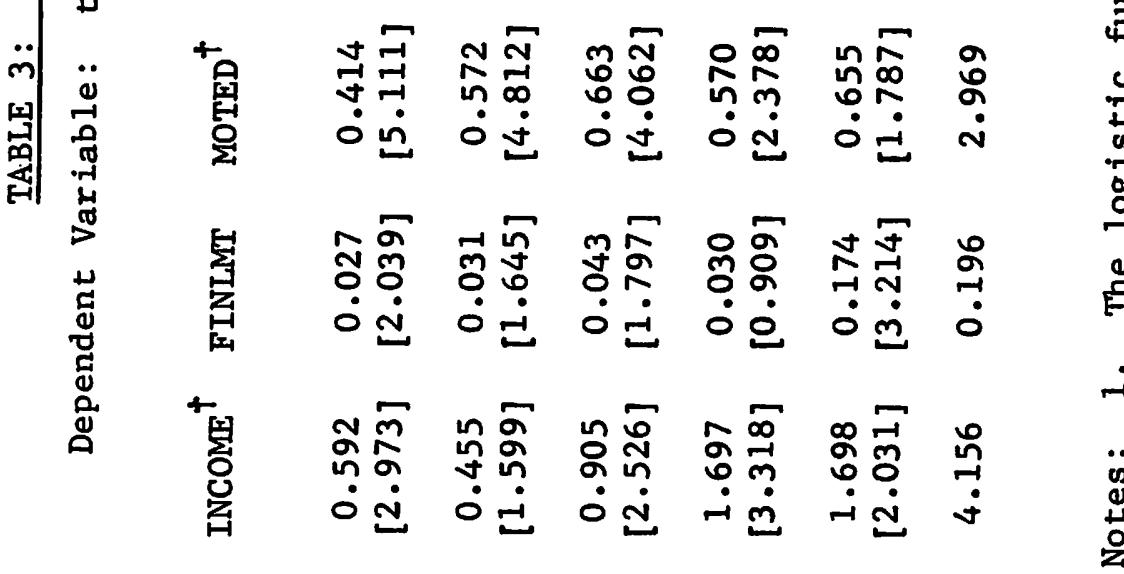

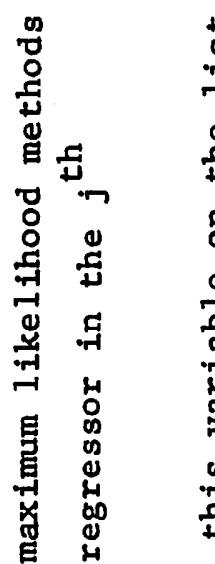

$\stackrel{\text { d }}{\nu}$

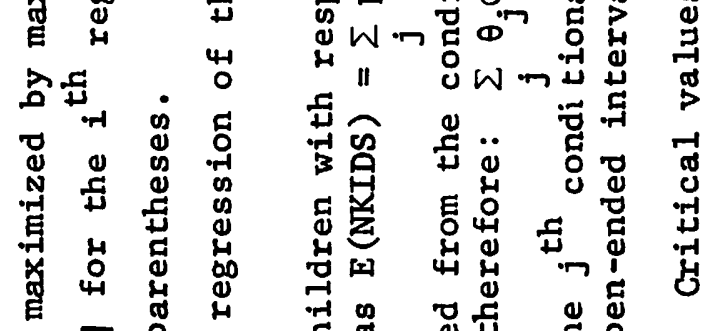

需

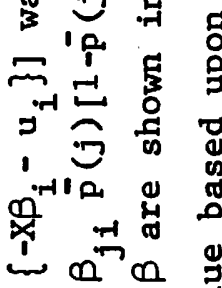

هั

$+\gamma^{m} \stackrel{0}{0}$

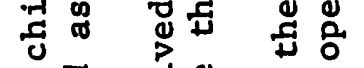

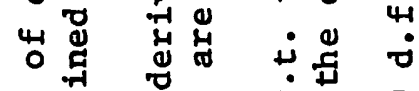

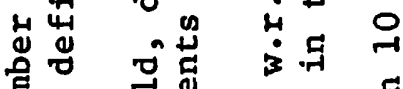

宝品

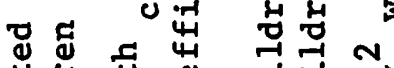

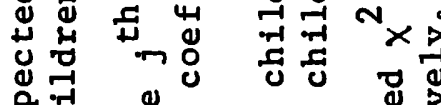

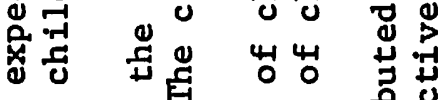

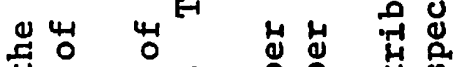

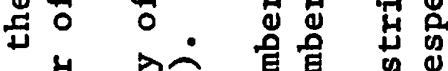

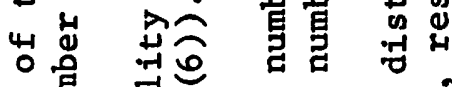

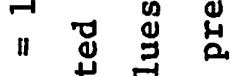

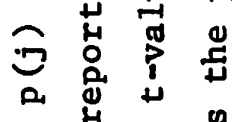

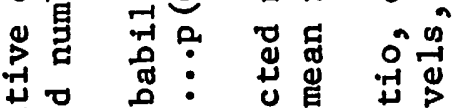

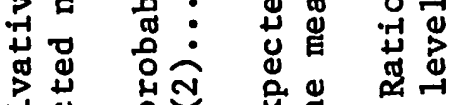

‥

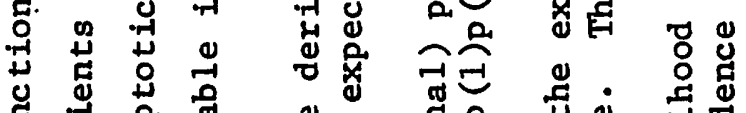

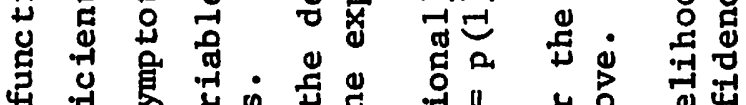

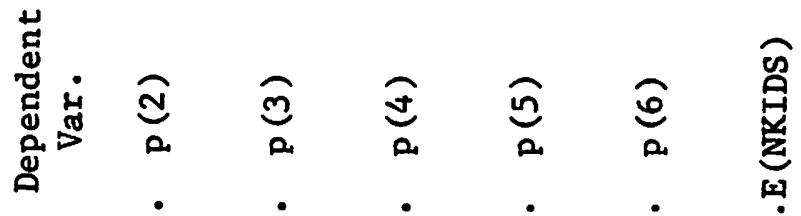

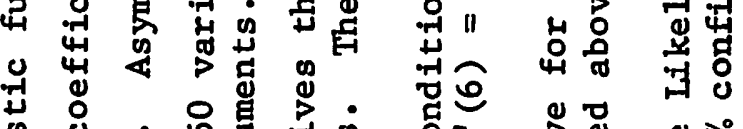

点 0 ¿

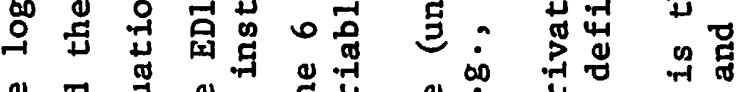

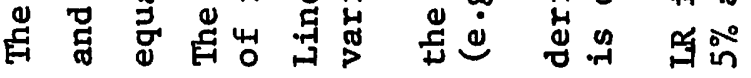

$\dot{j}$ 


\section{Additiona1 Results}

The rignificance of the SEX variable in the regressions for the whole sample and the results reported previously by Leibowitz (1974), suggest that the behavioral relations may differ between the male and female subsamples. The reduced form and structural equations were therefore estimated separately for these two groups. Table 4 reports results for females and for males.

For females, as with the whole sample, the INCOME variable is significant in both reduced form equations, being positive in the schooling equation and negative in the numbers equation, with elasticities of 0.20 and -0.68 , respectively. In contrast to the previous results the retrospective income variable FINLMT is never significant. The estimates of the structural equations for this subsample also offer strong empirical evidence in favour of the theoretical model. The INCOME variable, negative in the reduced form equation for numbers, enters with a significant positive coefficient in the structural equation, implying a positive true income elasticity. Mother's education which is negative but not significant in the reduced form fertility equation, enters with a positive coefficient in the structural equation. Also, MOTAGE which is negative in the reduced form equation, enters with a positive coefficient in the structural equation $(t=1.93)$, again implying increased productivity of women is associated with higher levels of fertility。 22 


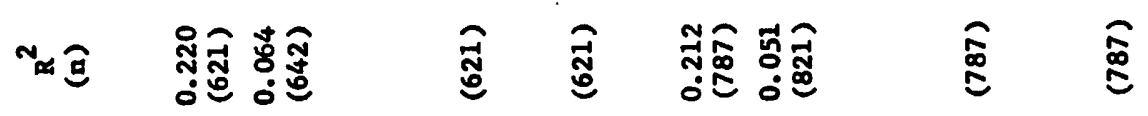
gु

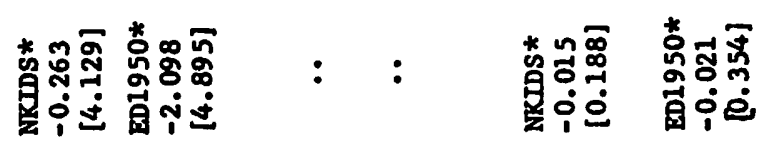

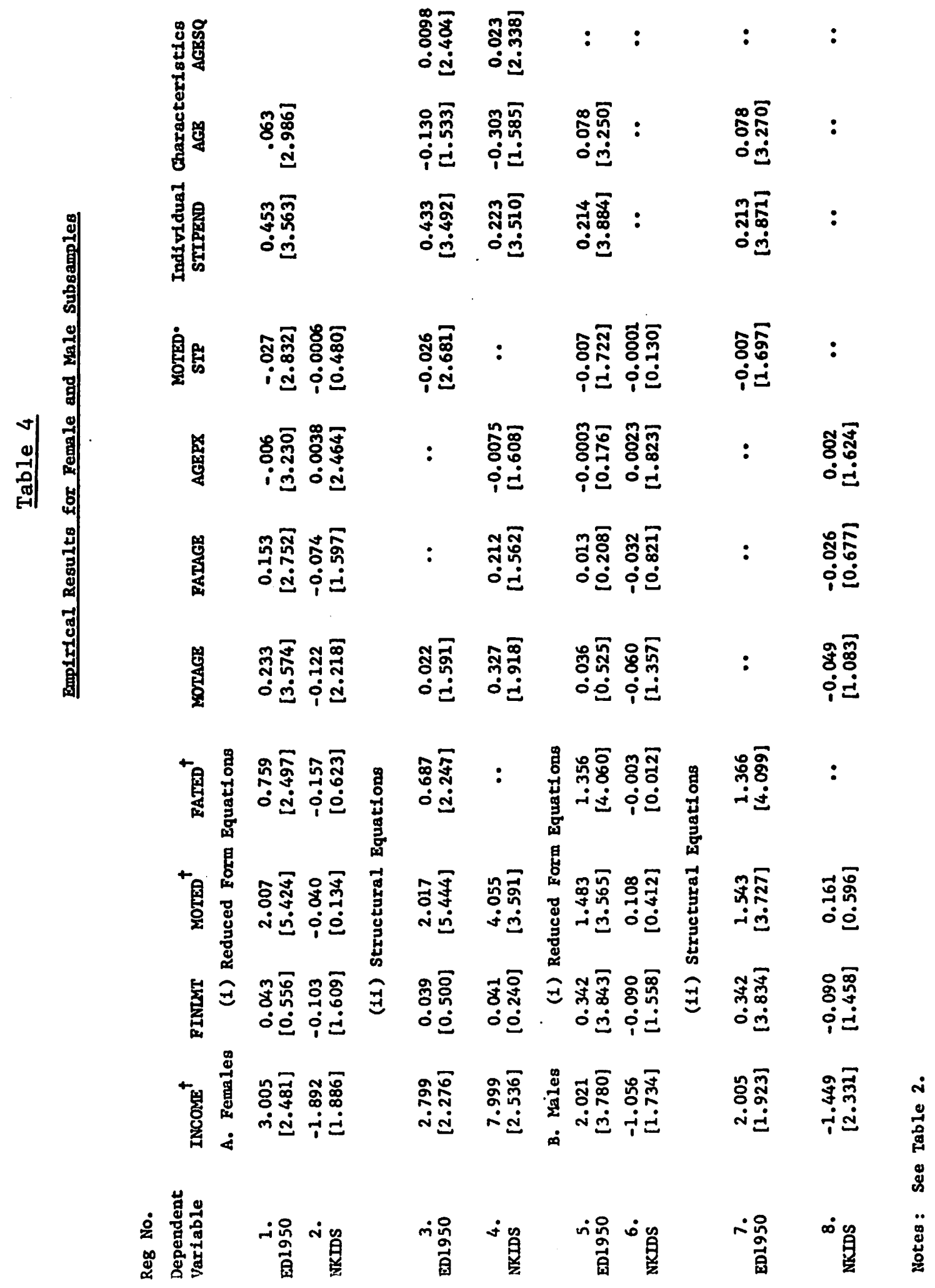


The results for the male subsample do not support the simple version of the quantity-quality interaction model. The income and parental education variables enter the reduced form schooling equation with positive coefficients. In the reduced form equation for numbers both income variables enter with negative signs but only the INCOME variable is significant at the $10 \%$ level. Of the other variables only the age interaction term is significant at the $10 \%$ level.

The estimates of the structural equations for the male subsample are in marked contrast to those reported for the sample as a whole and for the female subsample. For this subsample there is no evidence of quality-quantity interaction between schooling and fertility. Child schooling is not a significant determinant of fertility or vice versa. In addition, holding constant the level of schooling greater parental income is associated with lower levels of fertility implying a negative structural income elasticity for numbers. In addition the number of children is not significantly related to either mother ${ }^{8} \mathrm{~s}$ education or age, the two measures of parental efficiency.

The results for males may be analyzed in the light of the model in which the financial liability constraint is not binding and transfers take the form of both human and non-human capital. In this case since child's schooling does not represent the marginal form of transfers, the negative income elasticity of number of children may persist even when child schooling is held constant. This interpretation suggests that the financial constraints faced by the male subsample may differ from those encountered by the subsample of females. In the empirical results there is a little evidence in support of the hypothesis that the female subsample faced greater financial constraints with respect to their human capital investment. A FIRSTBORN dummy variable when introduced into the schooling equation entered as a significant determinant of the schooling of females, while this variable 
is not a significant determinant of the schooling of males. 23 This result suggests that females in this sample may have faced more stringent financial ' constraints than did males. However, the empirical findings concerning the effect of parental income on children's schooling do not support this interpretation. Although the theory suggests that if the male subsample were not constrained financially their schooling would be independent of income, the empirical results imply a positive relationship. ${ }^{24}$ The evidence concerning the differential incidence of the financial constraint is therefore mixed and in the absence of additional information concerning non-human capital transfers, the results for the male subsample must be viewed as inconclusive.

\section{Conclusion}

In the foregoing sections I have developed and subjected to empirical test, a simple version of the Quality-Quantity Interaction model of fertility. This version of the model embodies assumptions concerning the parental utility function and regarding the nature of the financial markets facing households. The model predictions are largely supported by the data. In particular fertility and children's schooling have been shown to be jointly determined and as a result of their interaction, the observed relationships of these variables to parental background variables have been shown to differ from the underlying true relationships. Although family size is observed to be negatively related to parental income and unrelated to mother's education, once child schooling is held constant family size was found to be positively related to both these variables, consistent with the predictions of the simple model. These results proved to be robust to the use of alternative estimation procedures. 
Although largely supported by these data, the simple model proved inadequate to explain the schooling and fertility of the male subsample. This finding suggests that when other forms of intergenerational transfers are taking place, such as non-human capital transfers, such transfers need to be incorporated into the model.

This paper has demonstrated the viability of the Quality-Quantity Interaction model in explaining the determination of completed family size. There exist alternative models which are also consistent with these observations. The model of Willis (1973) emphasizes the differential response of fertility to increased husband's income according to whether the wife is in or out of the labour force. Ben Porath (1973) proposes an alternative model which emphasizes the time intensity of children versus other household commodities and the possibility of factor intensity reversals. A test of these alternative explanations of household fertility would be desirable. 


\section{APPENDIX}

In this appendix I derive the structural demand functions of the model under the assumptions (i) that the utility function is homothetic CES, with equal elasticities of substitution between all commodities, (ii) that the financial liability constraint is effective for all households, so that all transfers take the form of human capita1, where parental inputs have a constant marginal product, (iii) there are flxed cost components associated with both numbers and quality. The parental income-expenditure constraint is

$$
I_{p}=p_{y} y+p n x+\bar{p}_{n} n+\bar{p}_{q} x
$$

where $\overline{\mathrm{p}}_{\mathrm{n}}$ and $\overline{\mathrm{p}}_{\mathrm{q}}$ are the fixed costs associated with numbers and quantity, respectively.

The marginal costs defined by the first order conditions are:

$$
\Pi_{y}=p_{y} ; \Pi_{n}=\vec{p}_{n}(\beta)+p x=\vec{p}_{n}^{*}+p q ; \Pi_{I}^{*}=\vec{p}_{q}^{*}+p^{* n}
$$

where $p_{j}^{*}=p_{j} / a(\beta)$ the "efficiency prices", and I assume an increase in $\beta$ reduces the three price components assoclated with quality and quantity $\left(\bar{p}_{n^{*}}^{*}, p_{q^{*}}^{*}, p^{*}\right)$ by the same percentage.

The level of household resources $R$ is :

$$
R=\underset{j}{\Sigma} \Pi_{j} j=I_{p}+\Pi_{I} e+p * n q
$$

Since endowments are assumed constant, the level of real resources can be shown to depend on real parental income and parental efficiency:

$$
E R_{r}=E R-E \Pi=\left(1-k-k_{e}\right) E I_{\bar{p}}+\left(k_{q}^{8}+k_{n}^{8}+k\right) E \beta
$$

where the $E$ operator denotes the $\log$ derivative, $R_{r}$ denotes real resources deflated by an index of marginal costs $\Pi_{,} I_{\bar{p}}$ is parental income deflated by an index of market prices $\bar{p}$ and the $k$ 's represent shares : 


$$
\begin{aligned}
k_{j} & =\frac{\Pi_{j}^{j}}{R}, k=\frac{p * n q}{R}, k_{e}=\frac{\Pi_{I} e}{R}, k_{n}^{8}=\frac{\bar{p}_{n}^{*} n}{R}, k_{q}^{8}=\frac{\bar{p}_{q}^{*} q}{R} \text { and } \\
k_{y}+k_{n}+k_{I} & =1, k_{n}=k_{n}^{8}+k, k_{I}=k_{q}^{8}+k+k_{e}
\end{aligned}
$$

The "true" demand functions written in compensated form are:

(A5) $\left\{\begin{aligned} E n & =E R_{r}-\left(1-k_{n}\right) \sigma E \Pi_{n}+k_{I} \sigma E \Pi_{I} \\ E I_{c} & =E R_{r}+k_{n} \sigma E \Pi_{n}-\left(1-k_{I}\right) \sigma E \Pi_{I} \\ E y & =E R_{r}+k_{n} \sigma E \Pi_{n}+k_{I} \sigma E \Pi_{I}\end{aligned}\right.$

where $\sigma$ is the Hicks-Allen elasticity of substitution and $p_{y}$ is assumed constant.

Substituting in the determinants of marginal costs and real resources, using the relationship in footnote 10 and solving for $n$ and $q$ gives the structural demand functions. If fixed costs represent the same proportion of total costs for both numbers and quality, these demand functions may be written as :

(A6)

$$
\left\{\begin{aligned}
E n=B_{I}^{-1}\left\{\left(1-k_{e}-k_{e}\right) E I_{\bar{p}}\right. & +\left[\left(\frac{1+s}{1-s}\right) k+k_{y} \sigma\right] E \beta-\left(1-k_{n}\right)(1-s) \sigma E q \\
& \left.-(1-s) k_{y} \sigma E p+s \sigma\left[k_{I} E_{p_{q}}^{-}-\left(1-k_{n}\right) E \bar{p}_{n}\right]\right\} \\
E q=\left[A B_{n}\right]^{-1}\left\{\left(1-k-k_{e}\right) E I_{-}\right. & +\left[\left(\frac{1+s}{1-s}\right) k+k_{y} \sigma\right] E \beta-\left(1-k_{I}\right)(1-s) \sigma E n \\
& \left.-(1-s) k_{y} \sigma E p+s \sigma\left[k_{n} E_{n}-\left(1-k_{I}\right) E \bar{p}_{q}\right]\right\}
\end{aligned}\right.
$$

where $s=k_{q}^{8} / k_{q}=k_{n}^{8} / k_{n}$ represents the share of fixed costs in the total costs of quality and quantity, $B_{I}=\left[1-A^{-1}(1-s) k \sigma\right]>0$ and $B_{n}=\left[1-A^{-1}(1-s) k_{n} \sigma\right]>0$, by the second order conditions that the "feedback" effects be dampened (i.e., nq to 0 ). Assume that the fixed cost components of numbers and quality are dependent on two sets of factors $\bar{p}_{n}=\bar{p}_{n}(\psi, \delta), \bar{p}_{q}=\bar{p}_{q}(\psi, \delta)$. The former set of factors 
are assumed to have a greater effect on the fixed cost component of quality than on the fixed cost of numbers, so that: $\eta_{p_{n}}=1, \underline{p}_{q}=1+\epsilon \epsilon>0$. The structural elasticities of quality and numbers with respect to $\downarrow$ are :

(A7) $\quad \frac{E q}{E \psi}=\left[A_{\circ} B_{I}\right]^{-1} s \sigma\left\{k_{n}-\left(1-k_{I}\right)(1+\epsilon)\right\}<0$

$$
\frac{E n}{E \psi}=B_{n}^{-1} s \sigma\left\{k_{I}(1+\epsilon)-\left(1-k_{n}\right)\right\} \gtreqless 0 \text { as } k_{I} \in \gtreqless k_{y}
$$

Similarly, the second set of factors are assumed to have a greater effect on the fixed cost of numbers, so that $\underset{p_{n} \delta}{\eta}=1+\lambda, \underset{p_{q} \delta}{\eta}=1, \lambda>0$. The structural elasticity of quality and numbers w.r.t. $\delta$ are:

$$
\frac{E q}{E \delta}=\left[\mathrm{AB}_{I}\right]^{-1} s \sigma\left\{k_{n}(1+\lambda)-\left(1-k_{I}\right)\right\} \gtreqless 0 \text { as } k_{n} \lambda \gtreqless k_{y}
$$

$$
\frac{E n}{E \delta}=B_{n}^{-1} s \sigma\left\{k_{I}-\left(1-k_{n}\right)(1+\lambda)\right\}<0
$$

In the text, the two sets of factors are specified as functions of the observable varlables: $\psi=\psi$ (FATED, MOTEDSTP) $\psi_{1}<0, \psi_{2}>0$ and $\delta=\delta$ (FATAGE,AGEPX) $\delta_{1}<0, \delta_{2}<0$. Also I assume that $k_{I} \epsilon=k_{y}$ and $k_{n} \lambda=k_{y}$, so that the model is identified (see footnotes 18 and 19).

If there are no fixed cost components associated with either quality or quantity (i.e., $s=0$ ) and the price of parental inputs to quality is constant, equations (A6) reduce to equations (10)'. Solving this system simultaneously gives the reduced form (observed) demand functions (11)', where the determinant $D$ is given by the following expression:

(A11) $\quad D \equiv\left[1-2 k_{I} \sigma-A^{-1} k_{y} \sigma^{2}\right]>0$

The second order condition that the determinant $D$ be non-negative implies that $\sigma<1$, since for $\sigma=1, D=-\left(1+k_{y} / k\right) k_{e}<0$, for any nonnegative level of endowments $\left(k_{e}>0\right)$. Since $I$ wish to allow for positive endowments, I assume $\sigma<1$, which implies that the coefficients $B_{n}$ and $B_{I}$, defined in (A6) above, are positive. 


\section{REFERENCES}

Becker, Gary S.; Land es, Elizabeth M.; and Michae1, R. T. "An Economic Analysis of Marital Instability," Journal of Political Economy 85, No. 6 (December 1977): 1141-1188。

Becker, Gary S.; and Lewis H. Gregg. "On the Interaction Between Quantity and Quality of Children," Journal of Political Economy 81, No. 2, Part 2 (March/April 1973): S279-\$288.

Becker, Gary S.; and Tomes, Nigel. "Child Endowments and the Quality and Quantity of Children," Journal of Political Economy 84, No. 4, Part 2 (August 1976): S143-S162。

Belmont, Io; and Morrolla, F。 "Birth Order, Family Size and Intelligence," Science 182 (December 14, 1973): 1096-1101.

Ben Porath, Yoram. "The Economic Analysis of Fertility in Israel: Point and Counterpoint," Journal of Political Economy 81, No. 2, Part 2 (March/Apri1 1973): S202-S233.

De Tray, Dennis N. "Child Quality and the Demand for Children," Journal of Political Economy 81, No. 2, Part 2 (March/April 1973): S70-S93.

Edwards, Iinda N॰; and Grossman, Michael. "An Economic Analysis of Children's Health and Intellectual Development," Working Paper No. 180, National Bureau of Economic Research, New York, May 1977.

Featherman, David and Carter, Michael T. "Discontinuities in Schooling and the Socioeconomic Iife Cycle," in Schooling and Achievement in American Society, W. H. Sewall and R. M. Hauser (eds.) (New York: Academic Press, 1976). Griliches, Zvi. "Wages of Very Young Men," Journal of Political Economy 84, No. 4, Part 2 (August 1976): S69-S85. 
Leibowitz, Arleen. "Women's Allocation of Time to Market and Non-Market Activities: Differences by Education," unpublished Ph.D. dissertation, Columbia University, 1972.

Leibowitz, Arleen. "Home Investments in Children," Journal of Political Economy 82, No. 2, Part 2 (March/April 1974): S111-S131.

Ifindert, Peter. "Sibling Position and Achievement," unpublished paper, University of Wisconsin-Madison, 1976.

Makhija, Indra. "The Work Done by Children in Rural Developing Societies : Effects on Fertility and Schooling," unpublished paper, University of Chicago, February 1978.

Press, S. James, and Nerlove, Marc. Univariate and Multivariate Log-Linear and Logistic Models (Rand, R-1306-EDA/NIH, December 1973).

Simon, Julian, Lo The Effects of Income on Fertility, Carolina Population Center , Monograph No. 19 (Chapel H111: University of North Carolina, 1974).

Tomes, Nige1. "A Model of Child Endowments and the Quality and Quantity of Children," unpublished Ph.D. dissertation, University of Chicago, 1978.

Willis, Robert Jo "A New Approach to the Economic Theory of Fertility Behavior," Journal of Political Economy 81, No. 2, Part 2 (March/April 1973): S14-\$64。 
FOOTNOTES

* This paper is based upon my Ph.D. thesis. I would like to thank, without implicating, the members of my committee: Gary S. Becker (Chairman), Gilbert R. Ghez and James J. Heckman. I also benefitted from comments by Michael Grossman and Linda Edwards. Responsibility for any errors is mine.

${ }^{1}$ See, for example, Belmont and Morolla (1973), Lindert (1976), Featherman and Carter (1976) and Griliches (1976) for evidence of this relationship.

2 Parents are "pure" altruists in that they derive utility from the number and per capita income of children per se, rather than from reciprocal child-parent transfers, labor services,"old age support", the consumption of designated "merit" goods or other forms of behavior which generate income or yield utility to parents.

${ }^{3}$ Becker and Tomes (1976) have shown that if the parental utility function is characterized by the property of "child neutrality" and if the marginal cost of transfers to each child is the same, parents will equalize the income of all children as a result of maximizing parental utility.

${ }^{4}$ Tomes (1978) considers the more general case where endowments differ across households within a generation. Further, Tomes (1978) and Becker and Tomes (1976) consider differences in endowments within households. In the empirical specification of the model (section 3), I allow for differences between the endowments of an individual child and the household mean. However, in these data it is not possible to distinguish between the effects of differences in mean endowments across families and differences within households given the same average endowment for all households. 
${ }^{5}$ Tomes (1978, pp. 158-163) considers alternative specifications of the effects of household efficiency in the quality-quantity interaction model and shows that in principle it is possible to distinguish empirically between alternative plausible specifications. The present specification is consistent with the observed propensity of women to withdraw from the labor force while "raising a family" and for this propensity to be positively related to the level of women's education (Liebowitz (1972)).

6More generally "fixed cost" components could be introduced which depend only on $n, X$ and $g$ as suggested by Becker and Lewis (1973). This generalization is examined briefly in the appendix.

${ }^{7}$ The second order conditions are examined in the appendix. Graphically since the budget constraint is curvalinear in $I_{C}$, $n$ space, the second order conditions require that the indifference curves be more convex to the origin than the relative marginal cost curve. If all commodities have equal elasticities of substitution, this elasticity must be less than unity.

${ }^{8}$ I assume that at the endowment position parents desire to make positive net transfers to the next generation. Also I assume that at the endowment point the marginal cost of human capital transfers lies below that of asset transfers so that it is always optimal to make positive investments in human capital. If the young could issue debt in order to finance human capital accumulation a similar solution to that mentioned in the text would obtain. I assume that capital markets do not exhibit a degree of perfection sufficient to permit the use of expected future earnings as collateral to secure debt.

${ }^{9}$ More general cases are considered in Tomes (1978) Appendix A. 
${ }^{10}$ From the income-generating function (2) the relationship of human capital transfers (q) to the demand for the per capita income of the next generation can be derived. Since endowments are assumed constant within a generation $d q=d I_{C}$, or in percentage change form:

$$
\mathrm{d} \ln \mathrm{q}=\frac{\mathrm{dq}}{\mathrm{q}}=\frac{\mathrm{I}_{\mathrm{C}}}{\mathrm{q}} \frac{\mathrm{dI} \mathrm{C}}{\mathrm{I}_{\mathrm{C}}}=\frac{1}{\mathrm{~A}} \mathrm{~d} \ln \mathrm{I}_{\mathrm{C}}
$$

where $A=q / I_{C}, 0<A \leq 1$. This relationship is used in (10)'.

${ }^{11}$ Similar statements apply to the effects of an increase in parental income. Also, since the share of transfers in children's income (A) is predicted to increase with parental income and efficiency, the model predictions are consistent with the observed ' $U$ '-shaped relationship between numbers and parental income (Willis (1973)) and the "transpose-J" relationship between family size and mother's education observed by Ben Porath (1973).

${ }^{12}$ In this section the marginal cost of human capital transfers is again assumed to be increasing and that of asset transfers is assumed to be constant. Marginal transfers therefore take the form of assets.

${ }^{13}$ The predictions concerning the effect on numbers of an increase in parental efficiency in this context are more complex, ambiguous in sign and not related in a simple manner to the observed demand function.

14 The comparative statics exercises of the previous section were carried out under the assumption that the vector of market prices, including the wage rate, were held constant. Elsewhere (Tomes (1978), pp. 161-163)) I have analyzed the effects of changes in parental efficiency which also affect market 
prices. The results of that analysis show that (i) if increased parental efficiency increases home productivity and market productivity (wages) by the same amount (i.e., there is "neutrality" in this sense) the relative prices of all conmodities will be unaffected. However, the income effect remains and therefore the predictions are unchanged. (ii) If the increased efficiency (assumed under (i)) occurred when women were non-labour force participants it would represent an increase in the supply of "efficiency units of female time." This would reduce the price of commodities which use female time intensively. If, following other authors, children are assumed to fall in this category, the price of this commodity would fall relative to other commodities and there would be a substitution effect reinforcing the income effect and once again the predictions of the model would be unaffected. ${ }^{15}$ Greater marriage specific investments may be reflected in either greater numbers of children or greater investments per child, or both. Since the greatest "period of risk" of divorce or separation occurs in the initial years of marriage (cf. Becker et al. (1977)) one might expect these factors to be reflected to a greater degree in the choice of family size, since this variable is determined prior to the level of investment in child's schooling.

Also in preliminary regressions a variable was introduced which interacted the education level of parents. However this variable was never significant and was therefore excluded in the later analysis.

${ }^{16}$ The structural demand equations implied by the theory can be written as:

$$
\begin{aligned}
& \text { (i) } \mathrm{n}=\delta_{\mathrm{n} \sim} \mathrm{X}+\delta_{1} \overline{\mathrm{q}} \\
& \text { (ii) } \overline{\mathrm{q}}=\delta_{\mathrm{q} \sim}^{\mathrm{X}}+\delta_{2} \mathrm{n}
\end{aligned}
$$

where $\mathrm{X}$ is the vector of exogenous variables and $\bar{q}$ is the average per capita 
transfer within the family. Intrafamily inequality in transfers may result from differences in the endowments of individual children relative to the mean for the family. The inequality of transfers relative to the household mean may be related to observable individual characteristics such as birth order, sex and the amount of extra-family financial aid received by the individual child. I.e.,

$$
\text { (iii) } q_{i}-\bar{q}=\delta_{I} Z \text { i }
$$

where $q_{i}$ represents the schooling of the $i^{\text {th }}$ child and $z_{j}$ is the vector of individual characteristics of the $i^{\text {th }}$ child. Substituting (iii) into (i) and (ii) gives:

$$
\begin{aligned}
& \text { (i) })^{\prime}=\delta_{n \sim} X-\delta_{1} \delta_{I_{\sim i}}+\delta_{1} q_{i} \\
& \text { (ii)' } q_{i}=\delta_{q} X+\delta_{I} Z_{\sim i}+\delta_{2} n
\end{aligned}
$$

The corresponding reduced form equations for $n$ and $q_{i}$ are:

$$
\begin{aligned}
& \text { (iv) } \mathrm{n}=\left(1-\delta_{1} \delta_{2}\right)^{-1}\left(\delta_{\mathrm{n}}+\delta_{1} \delta_{\mathrm{q}}\right) \mathrm{x} \\
& \text { (v) } \mathrm{q}_{\mathrm{i}}=\left(1-\delta_{1} \delta_{2}\right)^{-1}\left(\delta_{\mathrm{q}}+\delta_{2} \delta_{\mathrm{n}}\right) \mathrm{x}+\delta_{\mathrm{I}_{\sim}} \mathrm{z}
\end{aligned}
$$

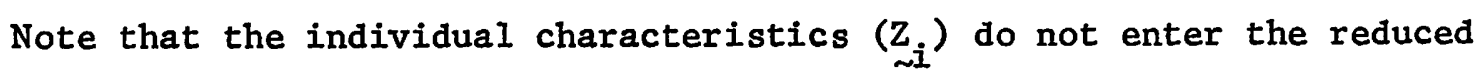
form equation for numbers (iv).

${ }^{17}$ See Tomes (1978), pp. 70-73. Edwards and Grossman (1977) examine a related model.

${ }^{18}$ The first assumption can be rationalized on the pragmatic grounds that while the MOTED-STP interaction term is predicted to enter the structural schooling equation with a negative coefficient, there is no clear prediction 
concerning the sign of this coefficient in the numbers equation. I impose the assumption that this interaction term has a zero coefficient.

If there exist fixed costs associated with child numbers and if father's education influences both the price of quality and the fixed cost of numbers, then for a special configuration of parameters, the structural demand for numbers will be independent of father's education (see equation A8 in the appendix). I assume this special configuration of parameters does in fact occur.

${ }^{19}$ As with the effects of parental education discussed in the previous footnote, the former assumption concerning the effects of father's age requires the inclusion of fixed cost components of quality and a special configuration of parameters (see equation A10 in the appendix).

The second assumption can be rationalized on the basis of the timing of fertility and child schooling decisions (see fn. 15).

${ }^{20}$ The following exogenous variables were used to generate the instruments : INCOME† FINLMT, MOTED† FATED†, MOTAGE, FATAGE, AGEPX, MOTED•STP, STIPEND, SEX, AGE, AGESQ, BIRTH ORDER. The latter variable was not introduced into the demand functions directly because, although an Individual characteristic of the child it is by construction correlated with the number of children. The vector of age variables represent a measure of birth rank that is not by definition correlated with family size.

${ }^{21}$ Since the model is overidentified the identifying restrictions can be tested by including one of the two excluded variables in each equation. The results confirm the identifying assumptions concerning the schooling equation, since neither FATAGE nor AGEPX is statistically significant when included. However in the numbers equation both FATED and MOTED.STP were significant at 
the $5 \%$ level when introduced.

${ }^{22}$ When the identifying restrictions were tested individually, as was found with the whole sample, neither FATAGE nor AGEPX entered the schooling equation significantly。 When FATED was included in the numbers equation, this variable was not significant at the $5 \%$ level, indicating that for the female subsample these identifying restrictions could not be rejected on the basis of these tests. However, when the MOTED.STP variable was included in the NKIDS equation its coefficient was significant at the $5 \%$ level.

${ }^{23}$ This result is based upon the inclusion of the FIRSTBORN variable into the reduced form equation for schooling. The coefficient, significant at the $5 \%$ level, implied that firstborn children receive five months additional schooling as compared to later-born children, amongst the female subsample. However, this variable was not significant in the structural demand equations.

${ }^{24}$ If unobserved endowments vary across households and are positively correlated with the measures of parental income as seems plausible, then the positive income coefficient could be the result of this omitted variable. It can be shown that when the financial liability constraint is not binding endowments and human capital transfers will be positively related if endowments increase the marginal product of parental inputs. 